\title{
¿Cuatro columnas hacen una basílica? La iglesia de San Pedro de Tarragona en la Antigüedad tardía
}

\author{
Do four columns constitute a basilica? The church \\ of St Peter of Tarragona in Late Antiquity
}

\author{
KAREN ForTuny MENDO \\ Josep MARIA Macias SOlÉ \\ Institut Català d'Arqueologia Clàssica \\ Plaça d'en Rovellat, E-43003 Tarragona \\ kfortuny@icac.cat \\ jmmacias@icac.cat
}

Presentamos una nueva visión entorno a la problemática arqueológica de la iglesia de la iglesia tardoantigua de San Pedro en Tarracona, mencionada en el Liber orationum festivus, más conocido como el Oracional de Verona, y datado a inicios del siglo viII. Nuestro análisis se basa en la aplicación de las nuevas técnicas de documentación gráfica alrededor de las plazas d'en Rovellat y dels Àngels de la ciudad actual. Sus resultados nos permiten proponer el emplazamiento exacto y una restitución parcial de una iglesia que ha sido frecuentemente mencionada en la investigación reciente.

\section{PALABRAS CLAVE}

TARRACONA, BASÍLICA, ESCÁNER LÁSER, FOTOGRAMETRÍA

The aim of this article is to afford a new vision about the archaeological discussion of Late Antique church of Saint Peter of Tarracona, mentioned in the Liber orationum festivus, named as 'Oracional de Verona' and dated to the beginning of $8^{\text {th }}$ century. It's an analysis based on the application of new graphic documentation techniques around the Rovellat and dels Àngels squares of current city. Their results allow us to propose the exact location and partial restitution of a church that has been frequently mentioned in recent research.

\section{KEYWORDS}

TARRACONA, BASILICA, LASER SCANNING, PHOTOGRAMMETRY 


\section{Introducción y contexto de la investigación}

Proponemos $^{1}$ el emplazamiento exacto de la iglesia de San Pedro en la Antigüedad tardía a partir del análisis elaborado sobre los restos arquitectónicos hoy visibles en el entorno urbano de las plazas d'en Rovellat y dels Àngels. Esta zona del centro histórico de Tarragona ha sido afectada por las reformas que, a lo largo del siglo xx, han alterado el entramado urbano definido desde la etapa medieval. Por lo demás, la cartografía disponible desde el siglo XVIII define una estructuración urbana muy similar a la actual, donde los ejes de la muralla republicana y el foro provincial flavio han predeterminado el trazado de las calles. La construcción del antiguo mercado municipal en 1958, sede actual del ICAC, supuso el primer seguimiento arqueológico en esta área (Sánchez Real, 1990: 86 y ss.). En 1971 el Museo Arqueológico Provincial realizó la primera excavación en extensión (Berges, 1974), donde aparecieron restos tardoantiguos de notable entidad. A partir de los años ochenta han proliferado las excavaciones de urgencia (Remolà y Dupré, 1988; López, 1992; Güell, 1993; Piñol, 1997; Pociña et al., 1999; González, 2009; Bravo, Bru y Roig, 2014) (fig. 1).

Esta problemática arqueológica se ha abordado de manera recurrente porque la escasez y la complejidad de la información no han dado respuestas satisfactorias a la relevancia de los restos conservados. En este contexto, nuestra aportación es un documento complejo, al usar datos parciales, algunos sin referencia estratigráfica concisa, y relaciones arquitectónicas inconexas. No obstante, nuestro estudio permite avanzar en relación con las últimas interpretaciones de las fuentes literarias y arqueológicas.

El área de estudio se halla junto al cierre oriental de la muralla del siglo II aC, que mantuvo su función militar durante la Antigüedad tardía, sin necesidad de una reforma arquitectónica intensa. Nos hallamos dentro del primitivo núcleo militar republicano, donde las intervenciones arqueológicas no han permitido caracterizar su estructuración urbanística y solo podemos mencionar la proximidad con la poterna de la muralla conocida en época medieval como la portella dels jueus. Posteriormente, este sector quedó fuera del gran proyecto urbanístico flavio del siglo I dC: recinto de culto imperial, foro provincial y circo. Así, la zona estudiada, unos $5000 \mathrm{~m}^{2}$, quedó delimitada por la plaza forense y la muralla. Desconocemos su función específica, pero la estratigrafía constructiva, restos arquitectónicos y fragmentos decorativos hallados indican una afectación intensiva. Se trata de un espacio periférico del complejo que acogía las ceremonias del Concilium Prouinciae, pero no un recinto aislado. El sector comunicaba fuera murallas a través de la poterna y la puerta monumental del Rei, en referencia al castillo medieval próximo. Este último acceso mantendría una anchura similar con la puerta dels Socors conservada al norte de la ciudad (TED'A, 1988-89: 127), pero las diferencias constructivas entre ambas sugieren que la puerta del Rei pudo construirse posteriormente. Quizás en época flavia, como la porta triumphalis circense que conectaba la arena con la periferia urbana (cfr.

1. Partimos del trabajo final de máster Estudi de les restes arqueològiques a l'entorn de la plaça d'en Rovellat - plaça dels Àngels realizado por Karen Fortuny Mendo, en el marco del Máster de Arqueología del ICAC/URV/UAB y presentado el 13/09/2018. 


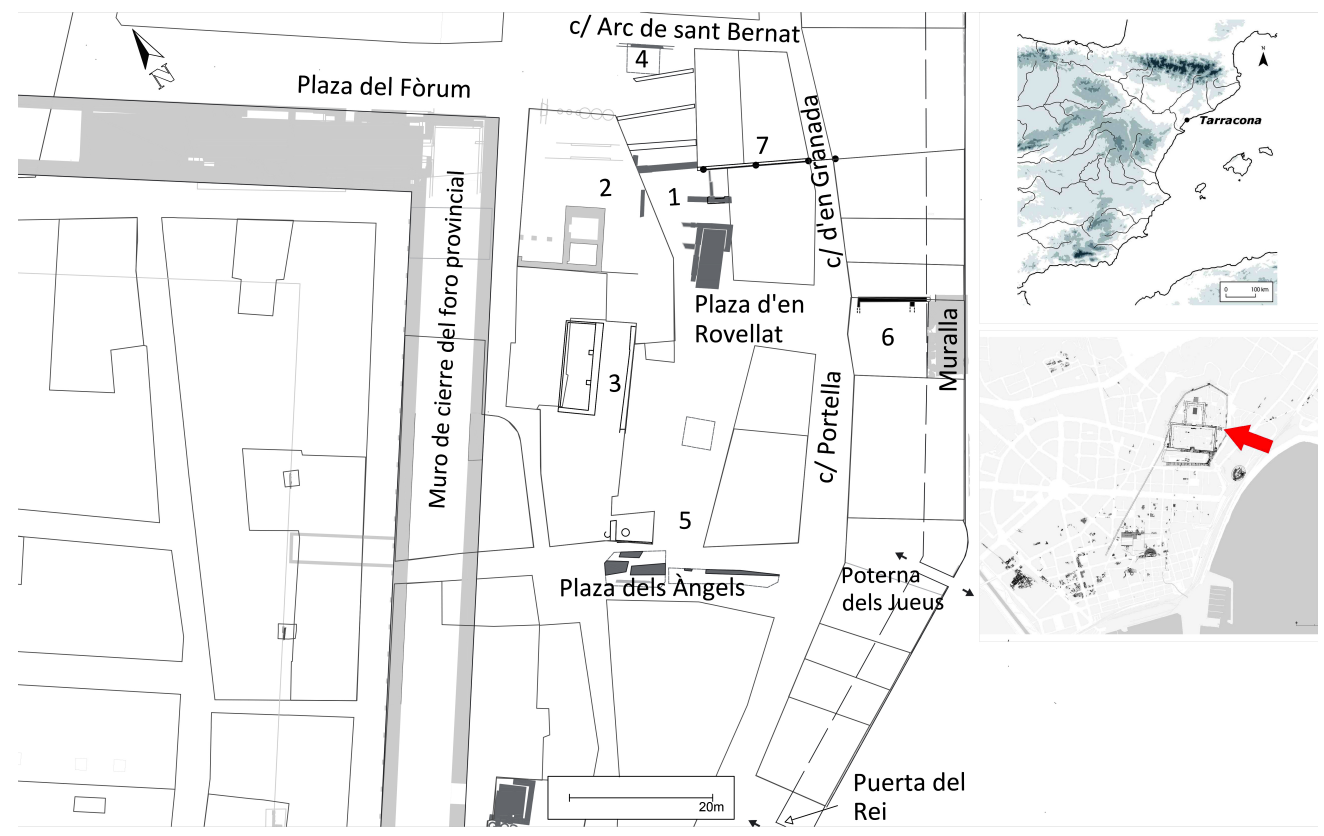

Figura 1. Planos de localización progresiva y zonas de excavación: 1) Pza. d'en Rovellat (Berges, 1974); 2) sede ICAC (Sánchez Real, 1990); 3) Ca la Garsa (Bea, Navarro y González, 2015); 4) sondeo c/ Arc de Sant Bernat (Pociña et al., 1999); 5) zanjas en pza. dels Àngels, 2-4 (Bravo, Bru y Roig, 2014); 6) Pza. d'en Rovellat, 1-2 (Piñol, 1997); 7) bajos, pza. d'en Rovellat, 9.

documentación en Martín y Rovira, 2009: 14-16). En el otro costado, el área estudiada conectaba con la plaza forense a través de una bóveda ubicada bajo el podio perimetral y sobreelevado de la plaza (cfr. Martín y Rovira, 2009: 55; Díaz y Teixell, 2014: 839).

Los procesos de transformación tardoantigua de Tarraco están también presentes en este sector, aunque se tiene de ellos un conocimiento parcial y diseminado. Solo podemos apuntar que a finales del Imperio un segmento próximo del criptopórtico perimetral del foro fue compartimentado para construir unos depósitos que, en los siglos v y vI, fueron reutilizados como espacios residenciales (Macias et al., 2007: ficha 85). Otros depósitos coetáneos fueron documentados en la plaza d'en Rovellat (Berges, 1974), así como varias estructuras aisladas. Estas evidencias son coherentes con la transformación funcional del complejo flavio a partir del segundo cuarto del siglo v: desacralización del témenos de culto imperial y aparición de residencias dentro de la plaza forense (Macias, 2013: 130). Desde finales del siglo v se detecta una transformación urbanística y arquitectónica más intensa: desmontaje del períbolos del témenos, cambios de circulación entre el foro y el circo, ocupación intensiva de la arena circense y desmontaje de los muros del foro provincial (Pociña et al., 1999). Es una época convulsa en que Tarraco recupera su relevancia geoestratégica al ser la última capital hispana bajo control imperial. Asimismo, como sede episcopal primada, 
las fuentes destacan su relevancia en el conjunto de la Iglesia hispana (Pérez, 2013: 241 y ss.). Es en este contexto que deben ubicarse las estructuras arqueológicas documentadas en las plazas d'en Rovellat y dels Àngels.

Las referencias contenidas en el Oracional de Verona reflejan las procesiones litúrgicas de Tarracona, a la vez que han suscitado un intenso debate en relación con la topografía eclesiástica de época visigoda (cfr. Arbeloa, 1987; Godoy y Gros, 1994; Macias, Menchón y Muñoz, 1997). En conjunto, la investigación arqueológica concluye que una sede catedralicia pudo haber reutilizado el antiguo templo de culto ubicado en la parte posterior del témenos altoimperial, tras el ábside de la ecclesia mater medieval. Este proyecto también se ha relacionado con la remodelación del extremo meridional del antiguo témenos de finales del siglo v (Macias, 2013: 140) y con abundantes indicios de un área funeraria privilegiada. La ubicación de la iglesia de Sanctus Petrus, citada en el documento, se ha situado en la zona que aquí estudiamos (Macias, Menchón y Muñoz, 1997).

La conquista musulmana interrumpió la vida colectiva organizada en la ciudad durante siglos (cfr. Gonzalo, 2013), pero a pesar de ello los espacios religiosos significativos de Tarracona debieron permanecer en la memoria colectiva y, quizás, en la misma fisonomía urbana altomedieval. Prueba de ello es la reutilización que sufrieron algunos durante la repoblación y recuperación de la sede eclesiástica. Ya a finales del siglo XI, se inició la reocupación eclesial del episcopio visigodo, con anterioridad a las obras de la catedral medieval (Muñoz, 2015: 211-212). La iglesia de Santa Maria del Miracle fue construida concienzudamente sobre la basílica visigoda del anfiteatro; mientras que la iglesia de San Fructuoso fue alzada cerca del foro colonial, donde la tradición situaba el juicio al obispo Fructuoso y sus diáconos (Menchón, Macias y Muñoz, 1994: 233). Para el caso que nos ocupa, una entrada del año 1174 del cartulario del monasterio de Poblet certifica la concesión por el arzobispo de Tarragona de los restos de una posible iglesia a este monasterio:

[...] illam voltam que dicitur antiquitus ecclesia Beati Petri, cum solo in circuito quod est infra menia civitatis Tarrachone, in villa antiqua iuxta murum prope turrim Poncii de Timor, quam tenet per Guillelmum de Cervari. Et sicut affrontat ab oriente in balnea antiqua et sicut est signatum a cantone balneorum versus plateam comunem, et a meridie in murum civitatis, et ab occidente in Solum Poncii predicti de Timor, et sicut tendit a cantone illius volte ad cellarium Arnaldi de Bitulonia defuncti, et a circio in platheam iam dicta [...] (citado en Macias, Menchón y Muñoz, 1997: 940).

La interpretación de las afrontaciones citadas en este documento ubica el recuerdo de la iglesia de San Pedro en esta zona. Por motivos que desconocemos, esta iglesia no fue recuperada y no consta en la relación de iglesias de la bula papal de Anastasio IV de 1154 (Muñoz, 2013: 117 y ss.). La arqueología urbana identifica en el área numerosas construcciones residenciales fechadas entre los siglos XIII y XV (Sánchez y Remolà, 2005; Ynguanzo, 2012; Bea, Navarro y González, 2015). En el sector meridional se establece el barrio judío medieval (Salvat y Bové, 1981: 361-383), intensamente transformado tras la expulsión de esta comunidad por los Reyes Católicos (Bea, Navarro y González, 2015: 99 y ss.). 


\section{Metodología}

A causa de la diversidad de fuentes y líneas de investigación, ha resultado necesario emplear una metodología flexible y plural con el fin último de proponer una lectura global y coherente del conjunto. Además de una extensa bibliografía, se ha consultado el material gráfico disponible, tanto la cartografía antigua accesible a través del Institut Cartogràfic i Geològic de Catalunya, como el fondo fotográfico del Arxiu Municipal y el Museu Nacional Arqueològic de Tarragona.

Nuestro objetivo metodológico principal ha sido la elaboración de una documentación gráfica propia sobre los restos arqueológicos hoy visibles. Esta tarea se ha juzgado necesaria ante la variabilidad en las condiciones de registro de las diferentes estructuras a lo largo del tiempo, cosa que ha generado una divergencia importante en la calidad y la tipología de su documentación. Así pues, siempre que ha sido posible se ha procedido a la interrelación topográfica y altimétrica de las estructuras arquitectónicas. Todas las cotas usan como referente el nivel del mar.

Para dicho fin, se han utilizado la fotogrametría y el escáner láser (fig. 4). La documentación del exterior ha usado el modelo C10 de Leica con frecuencia de longitud de onda, a partir de 16 estacionamientos, con una resolución de 1 punto/cm y una preci-

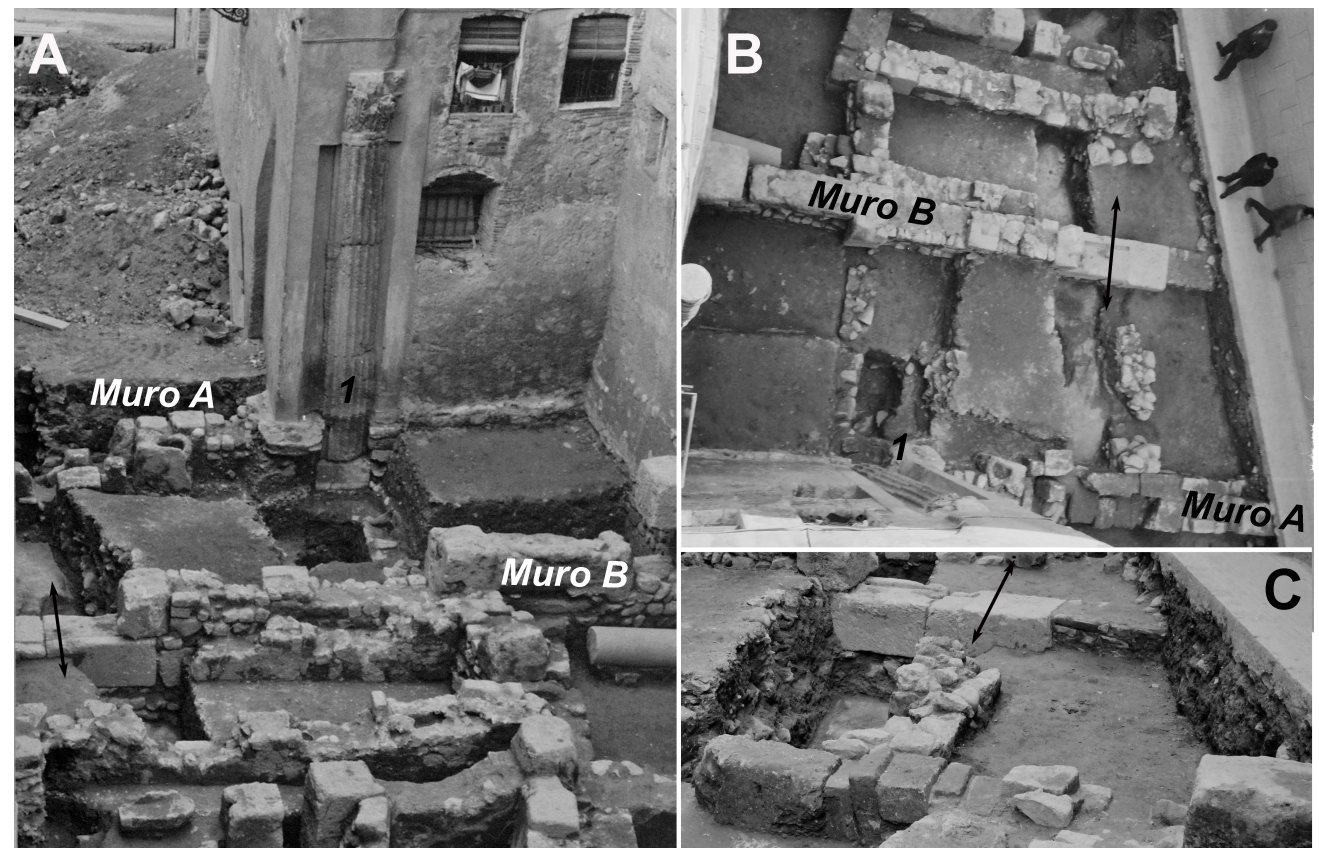

Figura 2. Fotografías de la excavación en plaza d'en Rovellat (1971) (autor: R. Vallvé. Fondo del MNAT): A) vista general de la excavación; B) perspectiva aérea con los muros A y B en primer plano; C) detalle del umbral en el muro B. 
sión de 2-4 mm, dando como resultado una nube de 80.000 millones de puntos. Para el escaneo de interiores se ha empleado el modelo de Leica BLK360, con una resolución de 1 pt/2-3 cm y una precisión de 2-4 mm, proporcionando una nube de 74 millones de puntos. Esta información ha generado un modelo virtual gestionado y tratado con el Leica Cyclone 3D Point Cloud Processing y el 3D Shaper. La georreferenciación se hizo a partir del portal virtual del ICC (sistema de referencia ETRS89). La fotogrametría ha usado el programa Agisoft PhotoScan (en un modelo de 123.359 puntos) a partir de imágenes obtenidas con una Nikon D610 de 20 mm de óptica. Las plantas, alzados y secciones han sido gestionadas con AutoCAD.

\section{Descripción}

Alrededor de la zona de la plaza d'en Rovellat, las primeras evidencias se hallaron en 1958, durante la construcción del nuevo mercado. Presumiblemente, debemos atribuir a época clásica una serie de muros construidos con grandes sillares, mientras que otros descritos por sus excavadores como "de técnica decadente» se consideran tardíos. Todos ellos presentaban una orientación más o menos ortogonal en relación con el muro de delimitación exterior del foro provincial (Sánchez Real, 1990: 87). Por sus características constructivas, los muros de sillarejo con grandes sillares verticales de refuerzo se han puesto en relación con las estructuras halladas en la plaza d'en Rovellat durante la principal excavación del año 1971, que cubrió unos $500 \mathrm{~m}^{2}$ de superficie. La metodología de registro de ambas actuaciones no permite establecer una secuencia temporal entre ellas, aunque se documentan algunas dinámicas estratigráficas comunes. Se han efectuado revisiones del material cerámico, por parte de S. Keay, X. Aquilué, J. A. Remolà y J. M. Macias, que consensuan la identificación de dos fases: la primera con base en estructuras domésticas e/o industriales alrededor de unos depósitos de la primera mitad del siglo v dC y un segundo proceso de abandono en el siglo vi (Aquilué, 1997). No existe relación estratigráfica directa con la columnata adyacente, descrita a continuación.

La intervención de 1971, dirigida por P. M. Berges, director del entonces Museo Arqueológico Provincial, sacará a la luz un importante conjunto de estructuras y material de decoración arquitectónica de época tardoantigua (Berges, 1974). Se documentan varios muros de cronología bajoimperial con una orientación ortogonal, más un depósito de líquidos y el principio de otro en los límites de la excavación. Los trabajos de derrumbe de antiguos inmuebles causan el descubrimiento in situ de la columna mejor conservada del conjunto (fachada posterior del n. ${ }^{\circ} 3$ de la calle Arc de Sant Bernat) (fig. 2a). Esta fue íntegramente elaborada a partir de material de expolio y conserva un basamento rectangular, el fuste, el capitel y un arco de medio punto bastante degradado y desplomado (Berges, 1974: fig. 3). A ambos lados de la calle posterior se conocen de antiguo dos columnas reutilizadas en sus fachadas y en notable estado de degradación: en la pared medianera 


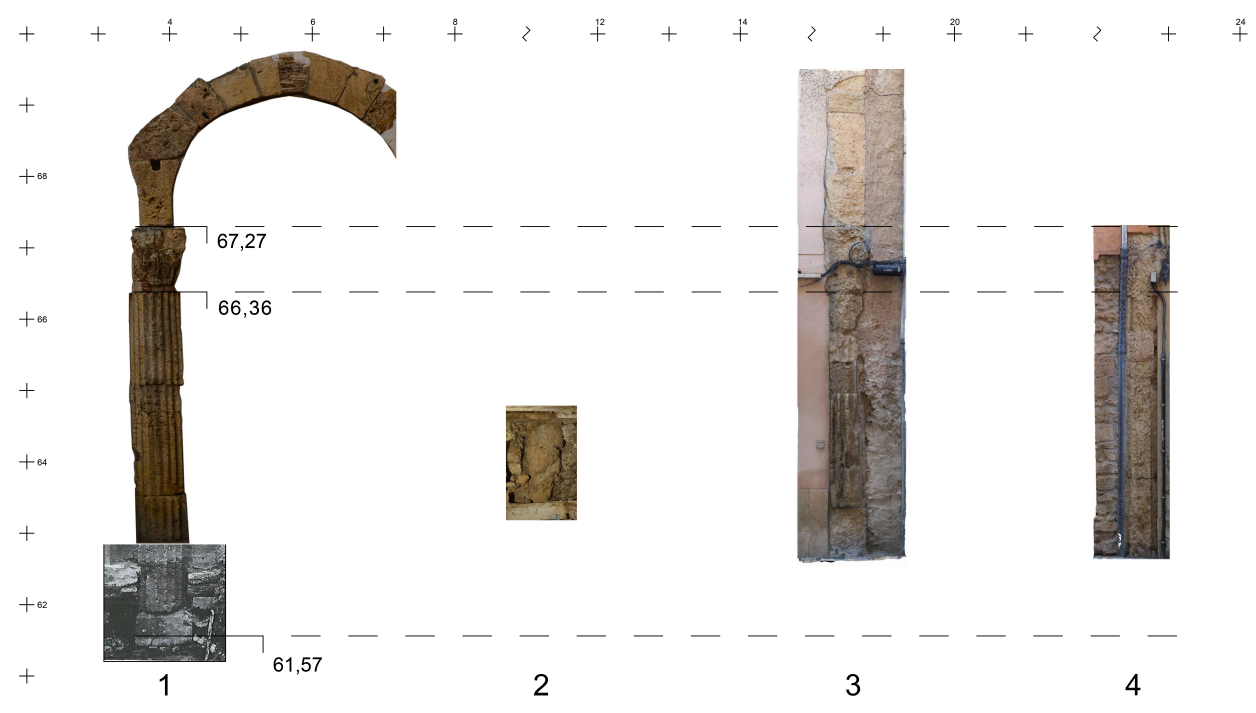

Figura 3. Composición fotogramétrica de los elementos visibles de la columnata. Añadida imagen de 1971 (Berges 1974: 157, fig. 3; archivo MNAT).

entre los $\mathrm{n} .{ }^{\text {os }} 9$ y 11 de plaza d'en Rovellat y entre las fincas de la calle Granada, 1, y plaza d'en Rovellat, 7. Berges documentó otra columna en la pared medianera de esta manzana de casas, sin precisar su ubicación exacta. La excavación sacó a la luz también varios muros tardíos. El muro "A» corresponde, según Berges (1974: 156), a la cimentación de la columna del Arc de Sant Bernat, 3, y, por extensión, de toda la alineación de columnas. El muro «B», todavía visible en la plaza, presenta características similares y conserva el umbral de una puerta de $230 \mathrm{~cm}$ de anchura (fig. 2b). En la documentación fotográfica se aprecia un acceso formado por dos grandes sillares, más otro vertical a modo de jamba. La imagen muestra un posible encaje longitudinal para una hoja (fig. 2c).

Las excavaciones en Ca la Garsa (plaza dels Àngels), en 2002, 2003 y 2009, cubrieron un solar de $400 \mathrm{~m}^{2}$ con diversidad de estructuras arqueológicas comprendidas entre la época romana y la baja Edad Media (Bea, Navarro y González, 2015). Son significativos los vestigios de los siglos XIII-XVI, algunos asociados con el barrio judío tarraconense. Aquí destacamos estructuras murarias tardías con una técnica cercana al opus africanum. Las excavaciones identificaron las habitaciones A y C, con dos bases de columna expoliadas, más el espacio de tránsito B (Bea, Navarro y González, 2015: fig. pág. 127). Sus excavadores ubican la construcción del conjunto entre los años 475-515 y 525 (Bea, Navarro y González, 2015: 126).

Más allá de estos dos focos principales, se ha documentado multitud de muros tardíos imposibles de fechar con precisión. Son estructuras de finales del siglo v y principios del vi bastante homogéneas en su orientación, adaptada a un esquema de retícula norte- 
sur y este-oeste. Respecto a las características constructivas, es difícil establecer conexiones ante la gran desigualdad de información. Se constata la reutilización de material de época altoimperial combinado con obra nueva de sillarejo (Remolà y Dupré, 1988; Güell, 1993; Pociña et al., 1999; Bravo, Bru y Roig, 2014). Más notable es el hallazgo de Jordi López y Lluís Piñol entre 1992 y 1995 en la plaza d'en Rovellat, 1-2 (Piñol, 1997). Es un muro fechado entre finales del siglo IV y el siglo $\mathrm{v}$, perpendicular y contiguo a la muralla. Conserva una altura de $5 \mathrm{~m}$; en él se detectan dos aperturas y funciona con un pavimento de mortero de buena calidad. También se documentan otros muros de menor entidad que permiten a sus excavadores inferir la existencia de dos ámbitos, mientras que J. J. Guidi y A. Villuendas (2012: 283, fig. 33) lo interpretan como un edificio de tres salas rectangulares para el cual, sin embargo, no acompañan con argumentación alguna. Su técnica combina hiladas regulares de sillarejo junto a grandes sillares dispuestos a modo de pseudo opus africanum (Macias, 2014: 462). Por último, mencionar el hallazgo fortuito en los bajos de la finca n. ${ }^{\circ} 9$ de la plaza d'en Rovellat de los restos de dos tambores no estriados de otra columna perteneciente a la alineación ya conocida.

\section{Análisis arquitectónico}

\subsection{La columnata de Rovellat-Granada}

Se establece una columnata en base a tres ejemplares visibles en la vía pública y otra documentada recientemente en los bajos de la plaza d'en Rovellat n. ${ }^{\circ}$ 9. Debe recordarse que P. M. Berges habla de otra columna que se encontraría insertada en el muro medianero de la manzana de casas, pero sin una referencia precisa. En cualquier caso, las cuatro columnas definen una alineación E-O que conforma un ángulo de $85^{\circ}$ respecto a la muralla tardorrepublicana y $83^{\circ}$, en relación al cierre del foro provincial. Su disposición sigue un intercolumnio uniforme de 2,90 m aproximadamente. Todas las medidas proceden del modelo 3D obtenido del escáner láser y la referencia de 2,90 m es la distancia entre las dos columnas de la calle d'en Granada. Su consideración como unidad de referencia, y no su distancia eje a eje (común en los análisis métricos), se debe a la dificultad de conocer con precisión el eje de las columnas conservadas, tanto por la inclinación del soporte mejor conservado, como por la alteración y erosión de los de la calle d'en Granada. A pesar de que el nivel de conservación hace imprecisa la medida del intercolumnio e impide hacer un cálculo exacto, consideramos que la imprecisión es mucho menor que en la distancia eje a eje.

Tras definir los 2,90 m, se ha observado en los bajos del inmueble la presencia de una pilastra moderna justo en el emplazamiento teórico de otra columna. Esta pilastra sostenía una viga de hierro reforzando los antiguos cabriones de madera. Suponemos que el albañil, ante la complejidad de perforar e insertar una viga de hierro en un hipotético tambor de 

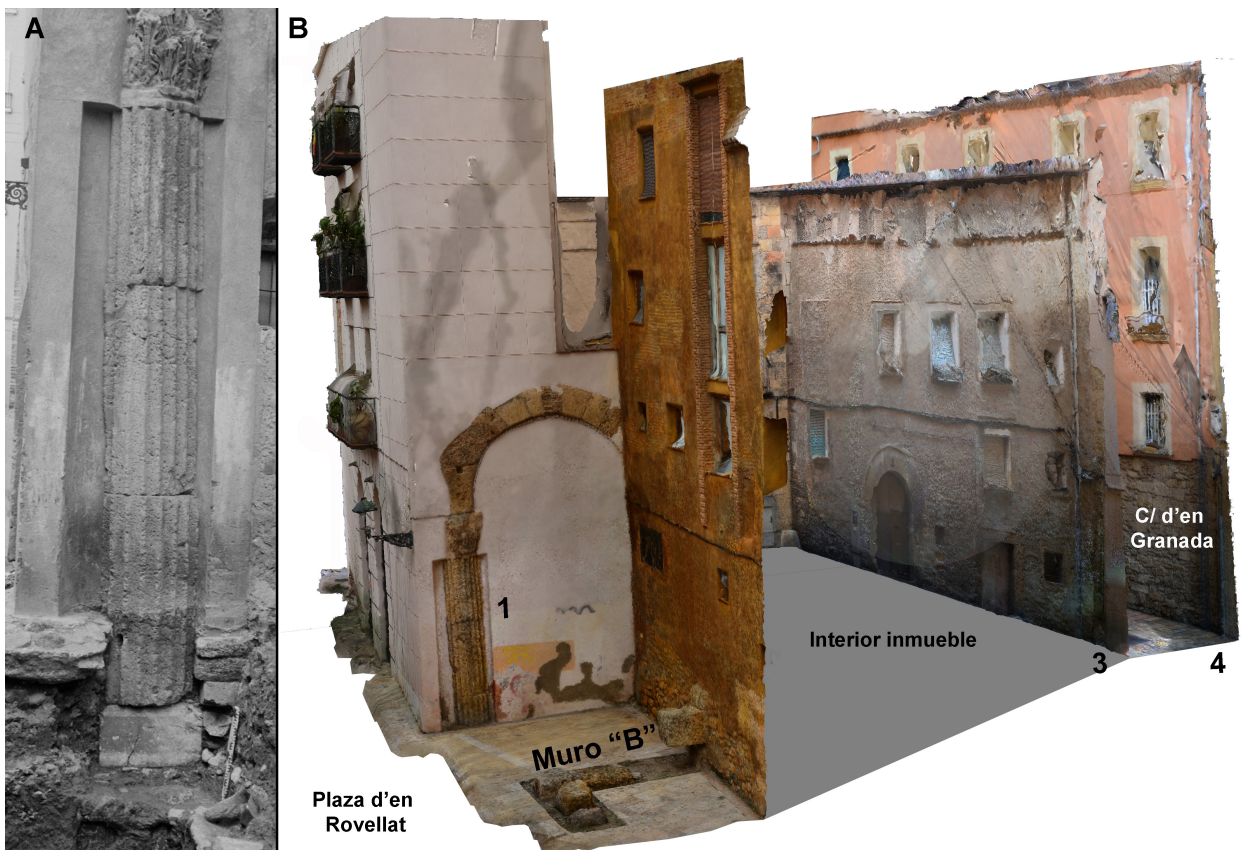

Figura 4. A) Detalle de la columna 1 (Berges, 1974: 157, fig. 3; archivo MNAT); B) modelo fotogramétrico parcial de la manzana Rovellat/Granada.

la columna de piedra, optó por construir un pilar de ladrillos adosado. Por último, debe tomarse en consideración la existencia de otra columna de fuste liso localizada durante los trabajos de construcción del mercado; a pesar de que no se puede ubicar con precisión, ha sido igualmente interpretada como la continuación de dicha columnata (Salom, 2009: 716 y fig. 33).

En cuanto a la correspondencia entre las cotas de las columnas, el nivel de conservación solo ha permitido relacionar dos de ellas. La comprobación de cotas entre los capiteles de la columna oriental de la calle d'en Granada y el de la plaza d'en Rovellat muestra una coincidencia perfecta: $66,36 \mathrm{~m}$ la cota inferior de los capiteles y 67,27 m, la superior. Un argumento más que confirma su integridad funcional (fig. 3).

\subsection{La relación de la columnata con las estructuras próximas}

Las deficiencias en el registro de la excavación de 1971 no permiten establecer una secuencia estratigráfica clara, ni relacionar temporal o funcionalmente las estructuras, mayoritariamente ocultas por la pavimentación actual de la plaza. La imprecisión del registro es el principal obstáculo que afecta las conclusiones del presente artículo, dado que nuestras observaciones se han basado en la revisión a posteriori de la documentación fotográfica y 
el estudio del material cerámico de X. Aquilué (1997). De las fotografías se infiere la cota de la pavimentación/base de la columna $(61,57 \mathrm{~m})$ y el inicio del primer fuste $(62,01 \mathrm{~m})$; también que el muro "A» de Berges, la cimentación corrida de la columnata, fue recrecido posteriormente (1974: 154 bis). Pero no podemos clarificar con certeza si los muros "A" $\mathrm{y}$ «B» eran paralelos. En la planimetría publicada consta que «B» es paralelo a " $\mathrm{C}$ », pero no a "A» (Berges, 1974: 154 bis). En cambio, en el diario de excavación de Lluís Papiol, ayudante de Berges y responsable de la documentación gráfica, que se había formado autodidácticamente en el Instituto Arqueológico Alemán de Madrid (Papiol, 2004: 69-70), se explicita claramente que los muros «A» $\mathrm{y}$ «B» eran paralelos (diario manuscrito conservado en el MNAT, 8-III-1971 y esquema de la planta en la pág. 1). No sabemos si esta sutil divergencia de trazado de ambos muros fue real o bien consecuencia del proceso de documentación; un aspecto que, como veremos más adelante, no afecta la interpretación de la planta del edificio.

Otro elemento a tener en cuenta es un pequeño muro perpendicular entre las paredes «A» $\mathrm{y}$ «B», a ras de su pavimento "constructivo-de uso" (nivel II de Berges, 1974: 159). Es un muro de factura tosca, que podría actuar como riostra o elemento de traba entre los dos grandes muros, indicando una clara relación estructural entre ambos. El pavimento mencionado es un nivel de "argamasa de cal y gravilla» de mala calidad que se documenta en puntos intermitentes alrededor del muro "A" (Berges, 1974: 158). Gracias a una fotografía antigua, que mostraba el alféizar de una ventana y el revestimiento de piedra del zócalo de la fachada actual, ha sido posible restituir la cota del umbral de puerta del muro «B» (en torno a 61,64 m), compatible con el nivel de uso de la pavimentación. Finalmente, también se detectó en superficie una serie de muros situados al noreste del muro "A», que no pudieron ser exhumados y que solamente aparecen esbozados en la planimetría de Berges (1974: 154). Aunque algunas lecturas los han interpretado como visigóticos (Guidi y Villuendas, 2012: 284, fig. 34), la falta de datos fehacientes nos lleva a mantenerlos al margen de este estudio.

La relación de las estructuras asociadas a la columnata con los restos descubiertos en las excavaciones próximas es aún más compleja. Los muros de Ca la Garsa, dispuestos en relación con el cierre del foro provincial, difieren de la alineación de la columnata en unos $15^{\circ}$ hacia el este. Referente a las cotas, hay, por ejemplo, una diferencia de 1,12 m entre la cota superior de la banqueta de cimentación de uno de los muros de Ca la Garsa $(60,45 \mathrm{~m})$ y la cota inferior de la base de columna de Rovellat $(61,57 \mathrm{~m})$. La diferencia refleja el desnivel general de la zona, de norte a sur. No se considera que esta diferencia de nivel excluya un funcionamiento coetáneo de ambas estructuras, si bien columnata y habitaciones deberían pertenecer a edificaciones diferentes. El último hallazgo procedente del entorno es un muro de cronología tardoantigua incierta que conserva restos de dos quicios situados entre los 59,99 y los 60,08 m, hecho que muestra la ligera pendiente de este sector urbano (Bravo, Bru y Roig, 2014).

Muy interesante es la posible relación entre el conjunto de Ca la Garsa y el muro hallado en la medianera de la finca d'en Rovellat, 1-2 (Piñol, 1997). En este último caso, 
el uso combinado de hiladas de sillarejo con grandes bloques verticales, aunque con un aspecto más tosco, es muy parecido al opus africanum empleado en los muros de Ca la Garsa. En este segundo solar se halló a 60,14 m un pavimento de mortero asociado a dicho muro (cota extraída de Piñol, 1997: 5). Solo existe una diferencia aproximada de $30 \mathrm{~cm}$, que no confirma ni excluye un funcionamiento coetáneo entre ambas estructuras, distanciadas unos $40 \mathrm{~m}$. Este hecho refleja una mayor "coherencia orográfica», mientras que el nivel de circulación en torno a la columnata se hallaría sobreelevado en relación con los edificios meridionales.

\subsection{La incógnita de una segunda columnata}

Uno de los asuntos más inciertos del sector urbano estudiado es la posible existencia de una segunda columnata paralela a la aquí estudiada. El origen de esta hipótesis se encuentra en una noticia de Hernández Sanahuja (1892: I, IIa, Ap. 1, 21), quien ubica, en la que hoy es la calle Portella n. ${ }^{\circ} 8$, dos columnas que relaciona con las del eje d'en Rovellat-Granada, interpretando que formarían parte de un mismo edificio de época imperial. A partir de esta cita, interpretaciones posteriores han presumido la existencia de un recinto porticado que incluía las dos columnatas (Salom, 2009: 723 y ss.; Macias, 2014: 461; Bea, Navarro y González, 2015: 126). A esta teoría se añade el descubrimiento, entre los años 2002 y 2009, de dos bases de columna en Ca la Garsa (Bea, Navarro y González, 2015: 132-134), que algunos también incluirán en este hipotético espacio.

Hernández Sanahuja asoció estas columnatas sobre la base de su proximidad y similitud estilística, interpretándolas como componentes de la perístasis de un antiguo edificio imperial. Esta descripción, no obstante, no aporta evidencias fehacientes de dos alineaciones paralelas, y un ulterior análisis métrico establece tres interrogantes. Primero, una columnata en el número 8 de la calle Portella implica una distancia de casi $50 \mathrm{~m}$ entre los dos ejes de columnas, una medida más que considerable para tratarse de una misma edificación. Por otro lado, las dos bases exhumadas en Ca la Garsa difícilmente pueden adscribirse a una estructura de estas características. Una se encuentra incrustada en un muro, reutilizada como material constructivo, y la otra aparece en posición exenta, aunque solamente a 0,70-0,85 m de separación respecto a un muro de esquina, un hecho disonante con la existencia de un espacio de tránsito. En tercer lugar, la distancia entre la cota inferior del basamento de la plaza d'en Rovellat $(61,57 \mathrm{~m})$ y la supuestamente conservada in situ en la esquina de Ca la Garsa $(60,03 \mathrm{~m}$ ) es de 1,54 m, coincidiendo con la pendiente orográfica natural de la zona. Cuesta aceptar que un hipotético recinto porticado tuviera un desnivel tan acentuado, ya que tampoco se han documentado estructuras de terraplén asociadas. Por todos estos motivos ponemos en cuestión si esta hipotética segunda columnata tendría una relación estructural con la que hemos estudiado. O siquiera si hubiera existido. 


\section{Un discurso interpretativo}

\subsection{Propuesta de restitución de la basílica}

La distancia útil entre la columnata y el muro «B» es de 3,53 m, medida equivalente a 12 pies romanos (estándar de 0,2957 m), mientras que el intercolumnio de la columnata es de unos 2,90 m, casi 10 pies. Medidas semejantes encontramos en Tarraco, como en la llamada basílica de Santa Tecla, del siglo v, con una nave lateral de 3,5 m y un intercolumnio de eje a eje de $3 \mathrm{~m}$ aproximadamente. La otra basílica suburbana, llamada de San Fructuoso, consta de naves laterales de 4,5 m y un intercolumnio de $3 \mathrm{~m}$. El último gran ejemplo local es la basílica del anfiteatro, del siglo vi o inicios del viI y algo más reducida: 2,15 m de anchura en las laterales y 2,20 m de intercolumnio (Muñoz, 2013: 101 y ss.). Por otro lado, la catedral de Egara, en su segunda fase de mediados del siglo v e inicios del vI, cuenta con naves laterales de 4 m e intercolumnio de 2,70 m (García, Moro y Tuset, 2009: 111). La basílica del Tolmo de Minateda presenta naves de planta irregular, que miden entre 3,85 y 3,10 m de anchura, la norte, y entre 3,75 y 3,50 m, la sur (se van estrechando hacia los pies), más una distancia entre columnas de 2,3-2,5m (Gutiérrez, Abad y Gamo, 2004: 139 y ss., medidas a partir de la fig. 1). Esta irregularidad se aprecia en parte de la documentación disponible para nuestro caso de estudio (v. apartado 4.2). Por último, la basílica de Son Peretó dispone de naves laterales de 2,80 m de anchura e intercolumnios aproximados de $2 \mathrm{~m}$ (Riera, 2009: 133).

A partir de esta hipótesis se plantea que la longitud de la columnata fuera más extensa de lo que se observa actualmente. Hacia el este, la proximidad de la muralla limitaría su continuidad, puesto que canónicamente aquí debe ubicarse el ábside. Por lo tanto, suponemos una arcada más coincidiendo con la esquina del arco triunfal. En el extremo opuesto, la situación de la puerta de acceso desarrolla la columnata, como mínimo, hasta este punto. De acuerdo con esto, debe señalarse que durante las obras del mercado se halló una columna de dimensiones similares un poco más al oeste de los restos hoy conservados. Por todo ello proponemos una basílica con una longitud de nave máxima entre los 32 y los 35 m, sostenida por una doble columnata de 9 pilares y 10 arcos u 8 pilares y 9 arcos. Optamos arbitrariamente por un ábside semicircular, con unas medidas teóricas condicionadas por el espacio disponible de 6,15 $\mathrm{m} \times 4,5 \mathrm{~m}(\mathrm{r}=1,36)$. Hallamos proporciones parecidas en la basílica del anfiteatro de Tarragona ( $\mathrm{r}=1$,23, Muñoz, 2013: 101), la de Santa Tecla ( $\mathrm{r}=1,5$, López, 2006: 111 ) o Santa Eulalia de Mérida (r=1,43, Mateos, 1999, medidas a partir de la fig. 30). En relación con la anchura hipotética de las naves, optamos por una proporción aproximada de 1-2-1 (fig. 5a) con base en la monumentalidad que denota la altura de las columnas y los paralelos existentes. Hallamos esta ratio (r: 2), respecto de la nave central, en San Apollinare in Classe en Rávena (De Angelis, 1962: 26) o en Santa Tecla del suburbio tarraconense (López, 2006: 109), aunque también existe una alta variabilidad en las basílicas tardías: desde edificios monumentales en Italia, por ejemplo, Santa Maria Maggiore (r: 2,35, Pensabene, 2015: 259), a los ejemplos hispánicos más reducidos, como la basílica del anfiteatro (r: 1,5, Muñoz, 2013: 101). 


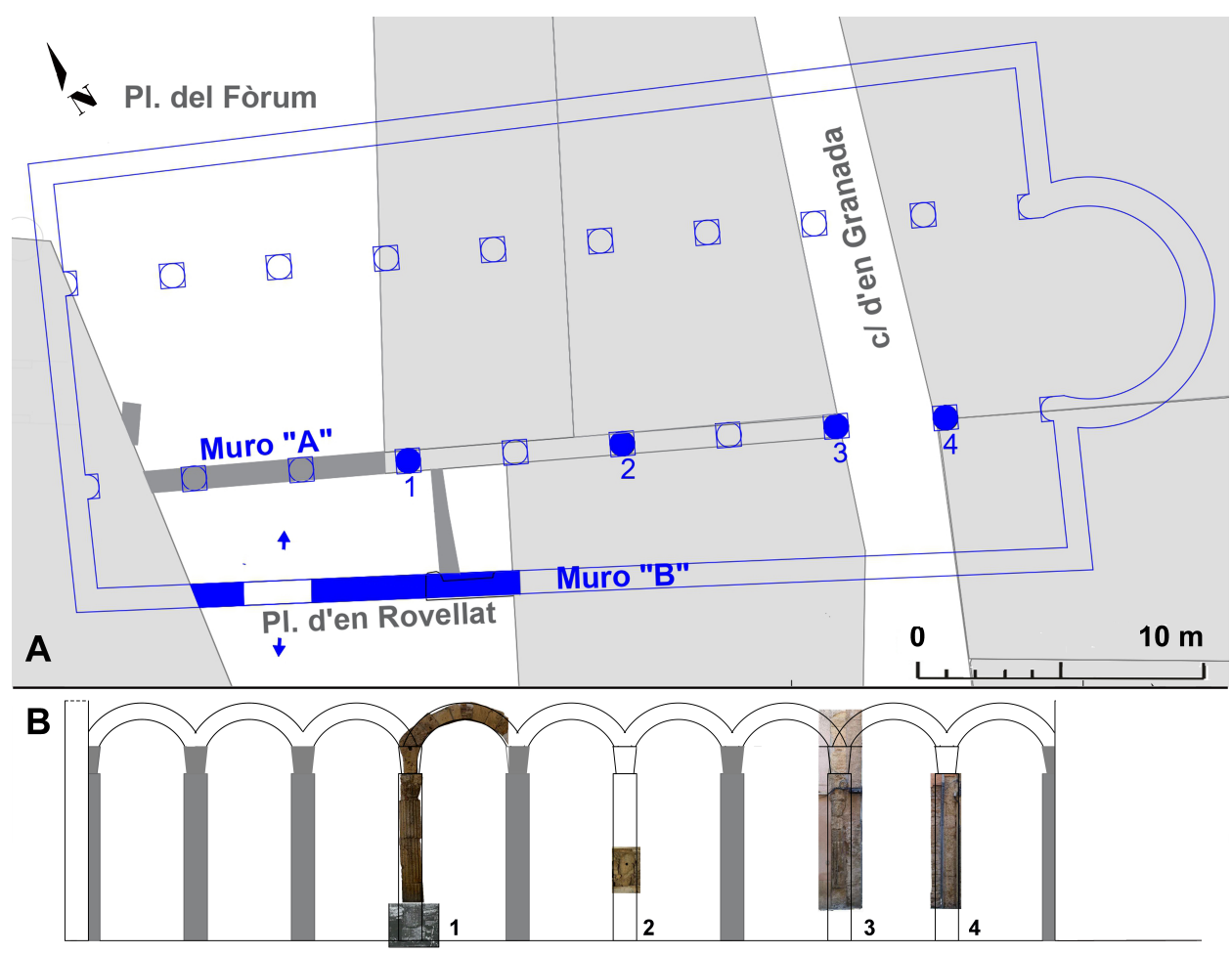

Figura 5. A) Propuesta restitutiva para la iglesia de San Pedro; B) alzado de la columnata.

La recreación volumétrica de la basílica es difícil de concretar con los escasos datos disponibles. A modo de apunte, comentar que la proporción entre la altura de la columnata (5,70 $\mathrm{m}$ desde la cota inferior de la base hasta la parte superior del capitel) y la anchura de la nave lateral $(3,53 \mathrm{~m})$ es de 1,615, una razón muy cercana a la proporción áurea $(\varphi)$, tal como se observa en otras construcciones basilicales coetáneas (López y Puche, 2013: 156). Una proporción muy similar se observa en la iglesia del Espíritu Santo, denominada Anastasis Gothorum, en Rávena $(\mathrm{r}: 1,56)$, datada entre finales del siglo v y principios del VI, y uno de los pocos ejemplos de estas cronologías que conserva su alzado original (De Angelis, 1962: 22). En relación con la altura de las columnas aquí estudiadas, debemos suponer una basílica de dimensiones considerables (fig. 5b).

\subsection{Apreciaciones cronológicas}

En relación con la cronología de la basílica solo contamos con indicios indirectos, dada la ausencia de una estratigrafía constructiva asociada a la columnata. X. Aquilué estableció un límite post quem de finales del siglo v o siglo vi, con base en la amortización de los 
depósitos documentados por P.M. Berges. En efecto, la presencia de una variante 87A, y especialmente de una Hayes 104A — que a partir de su publicación asociamos a una posible variante A2, por la marcada inflexión en la pared interna-, confirmaría la fecha de abandono de los depósitos avanzado el siglo vi (cfr. Aquilué, 1997: 1178, fig. 3 n. ${ }^{\text {os }} 11$ y 12; Bonifay, 2004: 173 y 183; Cau, Reynolds y Bonifay, 2011: 5).

Ante la falta de elementos directos de datación, solo podemos hacer referencia a los hallazgos del entorno, teniendo en cuenta que en esta parte de la ciudad estamos ante un proceso de transformación amplio. En primer lugar, fueron halladas cruces caladas que se asocian a este edificio de culto, cuyas características muestran claros paralelos con los ejemplares de la basílica del anfiteatro (TED'A, 1990: 205-241 y 423-444). También destacamos dos placas marmóreas decoradas, descontextualizadas y vinculadas a la plaza d'en Rovellat por parte de C. Salom (2009). Una de ellas está rematada por un frontón triangular y presenta un encaje lateral que pudiera ser apto para su uso como cancel (fig. 6), aunque el mismo autor propone una lectura distinta (Salom, 2009: 691). El estudio de Salom profundiza el desarrollado previamente por P. de Palol (1953) y destaca las similitudes de estas piezas con el programa iconográfico de una reforma del siglo vir en el baptisterio merovingio de Saint Jean de Poitiers, lo que señala la posibilidad de una influencia común. El último análisis en profundidad del monumento francés considera la mayoría de estas placas hechas ex profeso para dicha reforma, aunque muy influidas por el marco iconográfico de la fase anterior (siglo vI) (Boissavit-Camus, 2014: 374).

En relación con las excavaciones próximas, las estructuras de Ca la Garsa deben fecharse en el siglo vi a partir del material cerámico aparecido en las zanjas de cimentación (Bea, Navarro y González, 2015: 126), mientras que los pavimentos asociados permiten afirmar un funcionamiento coetáneo con la basílica. El gran muro de la plaza d'en Rovellat, 1-2, fue fechado a finales del siglo Iv y el siglo $v$, aunque también se reconoce que el contexto cerámico era insuficiente. Otras estructuras documentadas puntualmente presentan un marco cronológico parecido, con niveles de uso y amortización de los siglos v y vi para el Arc de Sant Bernat (Pociña et al., 1999) y una propuesta de datación en el siglo v para la plaza dels Àngels (Bravo, Bru y Roig, 2014).

\subsection{Contexto histórico y preguntas sin resolver}

Si bien el siglo v representa la transformación funcional del gran complejo imperial, no será hasta finales de este y durante la centuria siguiente cuando detectemos procesos urbanísticos decisivos que, en lo que nos atañe, representan la implantación real de la Iglesia en la escenografía urbana. Hasta ese momento, el epicentro de la Iglesia se desarrolló fundamentalmente en el suburbium y a partir del culto martirial. No es un hecho aislado; los casos próximos de Egara, Barcino o Valentia reflejan la ascendencia episcopal en la monumentalización de las nuevas ciudades visigodas. En el caso tarraconense, la arqueología desarrollada en torno a la catedral medieval define un proceso de transforma- 

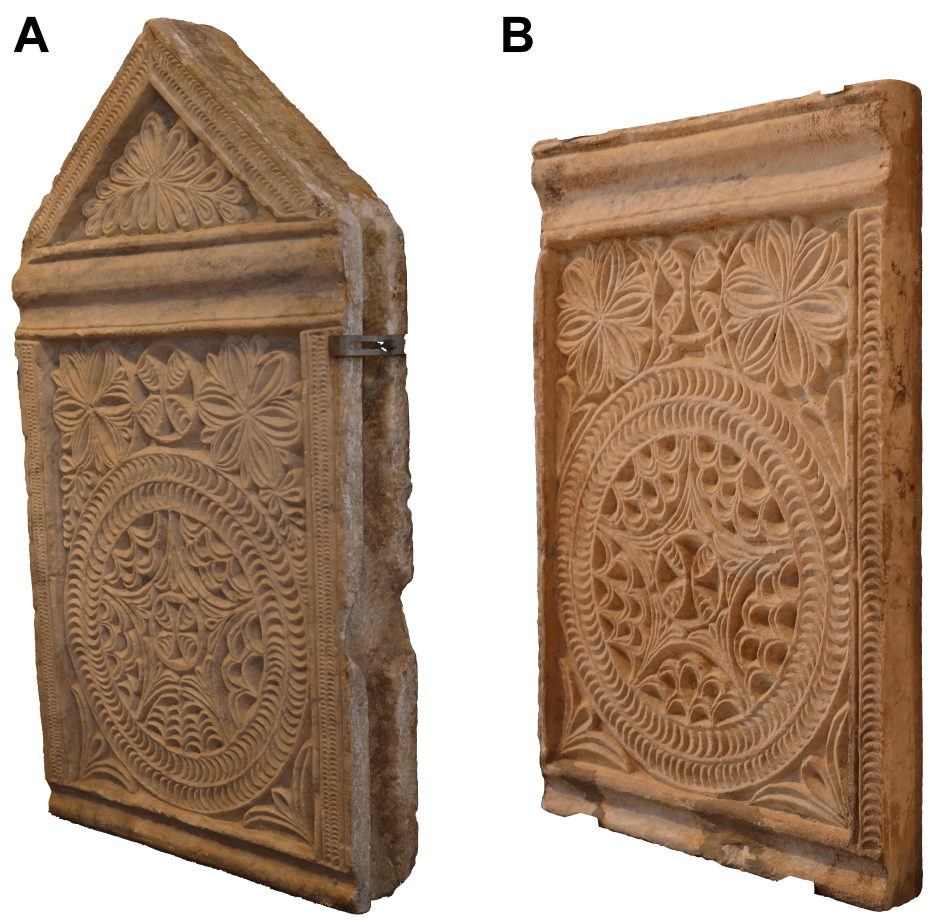

Figura 6. A) Placa con frontón recuperada en la c/ portella 19. Dimensiones: $116 \times 66 \times 12,3 \mathrm{~cm}(87 \mathrm{~cm}$ altura rectángulo y $29 \mathrm{~cm}$. frontón). Núm. Inv. MNAT-50448; B) placa recuperada en la zona portuaria. Dimensiones 86,5 x 57,5 x 5,8 cm. Núm. Inv. MNAT 19564. Fotos autores.

ción del antiguo recinto de culto pagano por iniciativa episcopal (Macias, 2013; Muñoz, 2015). Incluso se recuerda, sin ninguna relación directa segura, la celebración del concilio hispánico en Tarracona en el año 516. La iglesia de San Pedro debe situarse, a pesar de la imprecisión cronológica actual, dentro de este contexto. De este modo, podemos interpretar el desmontaje de la esquina nordeste del foro provincial, de finales del siglo v e inicios del vi (Pociña et al., 1999), como una medida necesaria para incrementar la visibilidad y la accesibilidad a la iglesia desde la antigua plaza del foro provincial.

No obstante, la cuestión fundamental de fondo radica en calibrar la importancia de esta basílica y el complejo arquitectónico que la rodea en el conjunto de la topografía y la liturgia cristiana de la ciudad. Los recientes resultados arqueológicos en Barcino (Beltrán de Heredia, 2017) han reavivado el debate sobre la dualidad arquitectónica católica y arriana, si bien no existe un lenguaje edilicio diferenciador que sirva de guía a la interpretación arqueológica. En el caso tarraconense la presencia del arrianismo se supone con base en indicios indirectos; así, por ejemplo, se ha planteado que la adscripción a San Pedro fuera la manera de integrar una antigua iglesia arriana (Pérez, 2005: 324); pero no hay ninguna evidencia cierta. 
Por otro lado, C. Salom (2009: 719) planteó la posibilidad de que este sector urbano fuera el episcopio tardoantiguo de Tarraco. Las cronologías establecidas impiden aplicar esta teoría para el episcopio del año 419 mencionado en la correspondencia entre Consencio y San Agustín, y del cual todavía no hay constancia arquitectónica. Pero ya en el siglo vi, plantearse una segunda sede episcopal es una posibilidad que no se puede desestimar. Actualmente solo podemos afirmar la existencia de un episcopio tardío en el extremo meridional del antiguo recinto de culto flavio (Aquilué, 1993; Macias, 2013: 142). En todo caso, sabemos que en el momento de la redacción del Oracional de Verona, a inicios del siglo viII, la iglesia de San Pedro no era la catedral visigoda ( $c f r$. Godoy y Gros, 1994; Serra, 2013). No obstante, este mismo documento refleja el protagonismo de la iglesia de San Pedro en la ritualidad de la Domenica in carnes tollendas.

En este contexto, la entidad y la concentración de edificios en este sector urbano deben tener alguna explicación y la dualidad de episcopios es algo más a tener en cuenta en el futuro. Al respecto, solo queremos apuntar una serie de diferencias a considerar. Por un lado, en el antiguo témenos hay varios datos referentes a la presencia de un área funeraria privilegiada, mientras que las evidencias funerarias en este sector son muy escasas y un tanto alejadas de nuestra área de interés (Gurt y Macias, 2002: fig. 3; Muñoz, 2015: 219-220). Por otro, el análisis de los materiales reutilizados en las basílicas de este período define una disponibilidad de material de acopio diferenciada, aunque seguimos sin contar con una base interpretativa sólida. En el caso de la basílica del recinto de culto no se han conservado elementos de decoración arquitectónica, mientras que en Rovellat todos los materiales son de piedra local y aparecen indistintamente fustes estriados y lisos. No podemos deducir la procedencia de los tres capiteles conservados in situ, y en las inmediaciones se ha recuperado un cuarto procedente del teatro y que, hipotéticamente, se ha asociado a esta columnata (Domingo, 2010: 808). En relación con la basílica del anfiteatro, todo indica que se reutilizaron los pesados fustes monolíticos de granito de la troade, procedentes con toda probabilidad de una reforma adrianea del templo de Augusto, situado en el centro del antiguo recinto de culto flavio (Rodà et al., 2012). Ambos casos reflejan una clara diferencia de capacidad técnica y/o disponibilidad económica, pero sobre todo de "carga simbólica".

Por último, debe tenerse en cuenta la posibilidad, ya apuntada, de vincular la iglesia de San Pedro a una comunidad monástica (Arbeloa, 1987: 131; Macias, 2014: 462). Es otra opción abierta, pero no hay evidencias arqueológicas directas ni existe una tipología urbanística monástica urbana para esta cronología que actualmente permita avanzar en ese sentido. También cabe apuntar, aunque sea en lo hipotético, la posibilidad de que el edificio de Ca la Garsa, por su envergadura, correspondiese a un edificio de naturaleza civil relevante.

\section{Reflexiones y perspectivas de futuro}

Aunque no podemos ser del todo concluyentes, creemos que la hipótesis más plausible es que los restos aquí analizados pertenecieran a la nave lateral de la basílica dedicada a 
San Pedro y mencionada en el Oracional de Verona. Es evidente que los indicios arquitectónicos — características de la columnata, relación sincrónica entre esta y el muro meridional «B», pavimentación de mortero de cal y umbral de la puerta- son en sí insuficientes para esta propuesta. En el apartado 5.1 hemos realizado, en cierto modo, un «ejercicio de paralelos» que justifica nuestra restitución, pero es el contexto histórico el que afianza nuestra teoría a la vez que permite introducir nuevos matices para la investigación futura. A la vez, es este mismo contexto el que nos hace descartar que nos encontremos ante las últimas evidencias de un pórtico monumental —que en este caso estaría inoperativamente orientado al norte- o bien un aula de recepción o atrium que también puede incluir columnatas.

Distintas excavaciones han sacado a la luz un importante conjunto de decoración arquitectónica con un carácter marcadamente eclesiástico en este sector urbano, y los restos aquí estudiados son los únicos que pueden adscribirse a un edificio de estas características. Además, cabe recordar otra vez el documento del año 1174 (Macias, Menchón y Muñoz, 1997: 940). Si retomamos la lectura de las "afrontaciones termales», debemos añadir dos cuestiones nuevas relacionadas con recientes excavaciones arqueológicas: illa voltam ... et sicut affrontat ab oriente in balnea antiqua et sicut est signatum a cantone balneorum versus plateam comunem. En las excavaciones ya mencionadas de Ll. Piñol (1995) en la calle Portella han sido documentadas sólidas estructuras y una estancia pavimentada en mortero, al este de la posible ubicación de la basílica. Dichas estructuras pudieran interpretarse en el siglo XII, por su solidez, como ámbitos residenciales, pero también como termales. Mucho más evidente es la reciente documentación de unas termas tardías en la actual calle de la Nau (Pociña, 2010) y cerca de la plaza del Rei, antigua plateam comunem, que añade más verosimilitud a la precisión topográfica del documento notarial medieval.

Si superponemos la planta hipotética de esta basílica en el catastro, constatamos que los muros medianeros entre las fincas plaza d'en Rovellat, 9-11, y calle Granada, 1-Rovellat, 7 corresponden a la alineación de la columnata (fig. 5a). En cuanto al cierre meridional de la basílica, muro " $\mathrm{B}$ ", este coincide con el muro maestro entre las fincas 11 y 13 de la plaza d'en Rovellat, e incluso puede apreciarse una ligera inflexión en la línea de fachada entre ambas casas coincidiendo con este eje. Por contra, el lado septentrional de la basílica se ha perdido en el transcurrir de los siglos y observamos un cambio en la disposición general de las casas a la altura del hipotético edificio. Esta inflexión se sitúa en la unión de las fincas 1 y 3 de la calle Granada. Las casas ubicadas al norte tienen una anchura media de $25 \mathrm{~m}$, mientras que las meridionales tienen una media de $15 \mathrm{~m}$. Al respecto, hay que tener en cuenta la noticia que relata que las fincas de la calle Granada n. ${ }^{\circ} 1-11$, junto la muralla, sirvieron para alojar al rey Carlos IV cuando permaneció en la ciudad con ocasión de la inauguración del puerto (Salvat y Bové, 1981: 307). De modo que, con anterioridad a la llegada del monarca, los nuevos edificios se adecuaron con el derrumbe de muros medianeros y la apertura de mejores accesos, lo que habría transformado — desconocemos hasta qué punto- la estructuración interna de esta manzana. 
A estas obras hay que añadir, como constata el mencionado documento del año 1174 , la edilicia efectuada por la orden benedictina en la calle Granada, 1, perpetuándose su presencia en este sector durante siglos (Salvat y Bové, 1981: 305-313). En este momento, la basílica de época visigoda ya estaría en gran parte destruida y las nuevas edificaciones se habrían guiado por los ejes omnipresentes de la antigua plaza flavia y la muralla republicana, condicionantes más sólidos del paisaje urbano. Hay que mencionar, como testimonio toponímico, que la calle que limita por el norte con el bloque de casas donde se encuentra la columnata se llama 'Arc de Sant Bernat', en referencia a los monjes del Císter. El nombre habla de un arco que fue derruido por orden del ayuntamiento a principios del siglo xx.

Somos plenamente conscientes de que los restos de esta columnata ofrecen otras posibilidades interpretativas y también que son necesarias más actuaciones arqueológicas — sondeos estratigráficos y prospecciones geofísicas - para la plena validación de nuestra teoría. Con este trabajo pretendemos solo plantear una posibilidad, a la vez que ofrecemos los resultados de un trabajo de documentación gráfica preciso y estricto. En definitiva, reivindicamos la necesidad de una lectura transversal y responsable de las distintas fuentes para encauzar un debate que todavía está lejos de cerrarse.

\section{Agradecimientos}

Esta investigación forma parte del proyecto Parámetros analítico-evolutivos de las técnicas constructivas del noreste de la Tarraconense en época tardoantigua (HAR2015-64392-C4-2P MINECOFeder) y del equipo de investigación de Arqueologia tardoantiga i cristiana (MIRMED-GIAC, ICAC/URV/UAB, 2017SGR970). Ha sido imprescindible la participación de la Unitat de Documentació Gràfica del Institut Català d'Arqueologia Clàssica, mediante el apoyo recibido de Josep M. Puche e Iñaki Matías y, muy especialmente, de Iván Fernández y Francesc Rodríguez. Agradecemos finalmente las facilidades recibidas de los Serveis Territorials d'Arqueologia de Tarragona y el Museu Nacional d'Arqueologia de Tarragona. 


\section{Bibliografía*}

AQUILUÉ, X., 1997, Referent a les estructures de l'antiguitat tardana de la plaça de Rovellat (Tarragona), Annals de l'Institut d'Estudis Gironins 37, 1169-1185.

ARBELOA, J. V. M., 1987, Per una nova interpretació del Codex Veronensis i les esglésies visigòtiques de Tàrraco, Butlletí Arqueològic V 8-9, 125-134

BEA, D., NAVARRO, S. y GONZÁLEZ, A., 2015, El call jueu de Tarragona. Estudi històric i arqueològic de l'edifici de Ca la Garsa i el seu entorn, Arola Editors, Tarragona.

BELTRÁN DE HEREDIA, J., 2017, Los nuevos hallazgos arqueológicos de la Basílica dels Sants Màrtirs Just i Pastor y la dualidad de baptisterios en Barcelona, en J. BELTRÁN DE HEREDIA y C. GODOY (eds.), La dualitat de baptisteris en les ciutats episcopals del cristianisme tardoantic. Actes del I Simposi d'Arqueologia Cristiana, Barcelona, FHEAGAUSP, 26-27 de maig de 2016, Studia Archaeologiae Christianae 2, 99-126.

BERGES, P.M., 1974, Columnas romanas y cruces visigóticas en la plaza del Rovellat, de Tarragona, en E. RIPOLL y M. LLONGUERAS (eds.), Miscelánea arqueológica. XXV Aniversario de los Cursos Internacionales de Prehistoria y Arqueología en Ampurias (1947-1971), vol. I, Institut de Prehistòria i Arqueologia, Barcelona, 153-167.

BOISSAVIT-CAMUS, B. (dir.), 2014, Le baptistère. Saint-Jean de Poitiers. De l'édifice à l'histoire urbaine, Bibliothèque de l'Antiquité Tardive 26, Brepols, Tournhout.

BONIFAY, M., 2004, Études sur la céramique romaine tardive d'Afrique, BAR Inter. Series 1301, Oxford.

BRAVO, P., BRU, M. y ROIG J. F. (CODEX), 2014, Memòria dels treballs arqueolòics amb motiu de la renovació d'un col-lector a la plaça dels Àngels, MIGC, Tarragona.
CAU, M. A., REYNOLDS, P. y BONIFAY, M. (eds.), 2011, An initiative for the revision of late Roman fine wares in the Mediterranean (c. AD 200700): The Barcelona ICREA/ESF Workshop, LRFWI, Archaeopress, Oxford.

DE ANGELIS D'OSSAT, G., 1962, Studi Ravennati. Problemi di architettura paleocristiana, Edizioni Dante, Rávena.

DIAZ, M. y TEIXELL, I., 2014, La plaza de representación del Concilium Provinciae Hispaniae Citerioris: Soluciones y dudas sobre su interpretación arquitectónica, XVIII CIAC, Centro y periferia en el mundo clásico, S. 8. Espacios y edificios públicos en el mundo greco-romano. Modelos y difusión, Mérida, 837-841.

DOMINGO, X., 2010, La reutilización de material decorativo clásico durante la tardoantigüedad y el altomedievo en Cataluña, Butlletí Arqueològic V 32, Tarragona, 795-848.

GARCÍA, G., MORO, A. y TUSET, F., 2009, La seu episcopal d'Ègara. Arqueologia d'un conjunt cristià del segle IV al IX, Documenta 8, ICAC, Tarragona.

GODOY, C. y GROS, M., 1994, L'Oracional hispànic de Verona i la topografia cristiana de Tarraco a l'Antiguitat tardana: possibilitats i límits, Pyrenae 25, 245-258.

GONZÁLEZ, A., 2009, Memòria de la intervenció arqueològica de ca la Garsa, plaça dels Àngels $n .^{\circ} 23$ de Tarragona (Tarragonès), MIGC, Tarragona.

GONZALO, X., 2013, La integración de Tarrakuna y su territorio en al-Andalus (s. viII), Arqueología y Territorio Medieval 20, 11-30.

GÜELL, M., 1993, Excavació a la Plaça dels Àngels, en R. MAR (ed.), Els monuments provincials de Tàrraco. Noves aportacions al seu coneixement, DAC 1, Universitat Rovira i Virgili, Tarragona, 229-244.

* Las memorias administrativas inéditas y depositadas en el Departamento de Cultura de la Generalitat de Catalunya aparecen referenciadas con las siglas MIGC 
GUIDI, J. J. y VILLUENDAS, A., 2012, Història, formació i usos de l'espai urbà i medieval a Tarragona, segles XII-XIII, Arola Editors, Tarragona.

GURT, J. M. y MACIAS, J. M., 2002, La ciudad y el territorium de Tarraco: el mundo funerario, en D. VAQUERIZO (ed.), Espacios y usos funerarios en el Occidente Romano, Universidad de Córdoba, Córdoba, 87-112.

GUTIÉRREZ, S., ABAD, L. y GAMO, B., 2004, La iglesia visigoda de El Tolmo de Minateda (Hellín, Albacete), Antigüedad y Cristianismo XXI (Sacralidad y Arqueología), 137-169.

HERNÁNDEZ SANAHUJA, B., 1892, Historia de Tarragona desde los más remotos tiempos hasta la época de la restauración cristiana..., editada, anotada $i$ continuada per E. Morera, Tarragona.

LÓPEZ, J., 1992, Memòria d'excavació de la plaça d'en Rovellat, núm. 1, MIGC, Tarragona.

LÓPEZ, J., 2006, Les basíliques paleocristianes del suburbi occidental de Tarraco. El temple septentrional $i$ el complex martirial de Sant Fructuós, Documenta 4, ICAC, Tarragona.

LÓPEZ, J. y PUCHE, J. M., 2013, Arquitectura paleocristiana de Tarragona (segles IV-V), en J. M. MACIAS y A. MUÑOZ (eds.), Tarraco christiana ciuitas, Documenta 24, ICAC, 149-163.

MACIAS, J. M., 2013, La medievalización de la ciudad romana, en J. M. MACIAS y A. MUÑOZ (eds.), Tarraco christiana ciuitas, Documenta 24, ICAC, 123-148.

MACIAS, J. M., 2014, El territorio y la ciudad de Tarraco, en P. PENSABENE y C. SFAMENI (eds.), La villa restaurata e i nuovi studi sull'edilizia residenziale tardoantica. Atti del convegno internazionale del Centro Interuniversitario di Studi sull'Edilizia Abitativa Tardoantica nel Mediterraneo (CISEM), Piazza Armerina, 7-10 novembre 2012, Edipuglia, Bari, 453-465.

MACIAS, J. M., FIZ, I., PIÑOL, Ll., MIRÓ, M. T. y GUITART, J., 2007, Planimetria arqueològica de Tàrraco, Documenta 5, ICAC, Tarragona.

MACIAS, J. M., MENCHÓN, J. y MUÑOZ, A., 1997, De topografia urbana cristiana de Tarragona, a propòsit de dos documents medievals, Annals de l'Institut d'Estudis Gironins XXXVII, 1996-97, Girona, 939-951.

MARTÍN, O. y ROVIRA, J., 2009, Arquitectura i urbanisme de la part alta de Tarraco en època republicana i imperial: gènesi, disseny i construcció, RSAT, Tarragona.

MATEOS, P., 1999, La basílica de Santa Eulalia de Mérida. Arqueología y urbanismo, Anejos de AEsPA XIX, CSIC, Madrid.

MENCHÓN, J., MACIAS, J. M., y MUÑOZ, A., 1994, Aproximació al procés transformador de la ciutat de Tàrraco. Del baix imperi a l'edat mitjana, Pyrenae 25, 225-243.

MUÑOZ, A., 2013, Sant Fructuós de Tarragona. Aspectes històrics $i$ arqueològics del seu culte, de l'antiguitat a l'actualitat, URV, Tarragona (tesis doctoral).

MUÑOZ, A., 2015, La qüestió arqueològica de Santa Tecla la Vella o les catedrals perdudes a Tarragona: de l'antiguitat al segle XII, en A. PUIG, A. PÉREZ DE MENDIGUREN y J. M. GAVALDÀ (eds.), El culte de Tecla, Santa d'Orient i d'Occident. Congrés de Tarragona, octubre 2011, Ateneu Universitari Sant Pacià, Tarragona.

PALOL, P., 1953, Tarraco hispanovisigoda, RSAT, Tarragona.

PAPIOL MOLNÉ, Ll., 2004, Memòries dels meus treballs arqueològics, Estudis de Constantí 20, Centre d'Estudis de Constantí, 69-116.

PENSABENE, P., 2015, Roma su Roma. Reimpiego architettonico, recupero dell'antico e trasformazioni urbane tra il III e il XIII secolo, Monumenti di antichità cristiana ser. II, vol. XXII, Ciudad del Vaticano.

PÉREZ, M., 2005, Tarraco christiana. Cristianización y organización eclesiástica de una capital provincial romana (siglos III al VII), URV, Tarragona (tesis doctoral).

PÉREZ, M., 2013, Obsessa Terrachona marithimas urbes obtinuit. L'impacte de la conquesta visigoda de Tàrraco per Euric segons les fonts escrites i l'arqueologia, Revista d'Arqueologia de Ponent 23, 237-248. 
PIÑOL, Ll., 1997, Memòria de la intervenció arqueològica al solar núm. 1-2 de la plaça Rovellat. Tarragona (Tarragonès) (octubre-novembre de 1995), MIGC, Tarragona.

POCIÑA, C. A., 2010, Memòria d'excavació al cl la Nau (Tarragona, Tarragonès), MIGC, Tarragona.

POCIÑA, C. A., REMOLÀ, J. A., PEÑA, I. y SALOM, C., 1999, Memòria d'excavació. Plaça del Fòrum (Tarragona, Tarragonès), MIGC, Tarragona.

REMOLÀ, J. A. y DUPRÉ, X., 1988, Memòria de les excavacions de la plaça dels Àngels (1986), MIGC, Tarragona.

RIERA, M., 2009, Enterramientos de la Antigüedad Tardía en las islas de Cabrera y Mallorca, en J. LÓPEZ QUIROGA y A. M. MARTÍNEZ TEJERA (eds.), Morir en el Mediterráneo Medieval. Actas del III Congreso Internacional de Arqueología, Arte e Historia de la Antigüedad Tardía y Alta Edad Media peninsular, 17 y 18 de diciembre de 2007, BAR Inter. Series 2001, Oxford, 99-151.

RODÀ, I., PENSABENE, P. y DOMINGO, J. A., 2012, Columns and Rotae in Tarraco made with Granite from the Troad, en A. GUTIÉRREZ, P. LAPUENTE e I. RODÀ (eds.), Interdisciplinary Studies on Ancient Stone Proceedings of the IX Association for the Study of Marbles and Other Stones in Antiquity (ASMOSIA 2009), Tarragona, 210-227.
SALOM, C., 2009, La arquitectura eclesiástica de Tarragona durante la antigüedad tardía, nuevas interpretaciones, Butlletí Arqueològic V 32, 685-757.

SALVAT I BOVÉ, J., 1981, Tarragona antigua y moderna a través de su nomenclatura urbana (siglos XIII al XIX), Ajuntament de Tarragona (edición facsímil).

SÁNCHEZ REAL, J., 1990, El método en la arqueología tarraconense. Las construcciones monumentales de la Parte Alta. II. B) El foro, Butlletí Arqueològic V 12, Tarragona, 49-98.

SÁNCHEZ, J. y REMOLÀ, J. A., 2005, Memòria d'excavació: cl Granada, núm. 9. Tarragona (Tarragonès), MIGC, Tarragona.

SERRA, R., 2013, La litúrgia de la Domenica in carnes tollendas en l'Oracional de Verona, en J. M. MACIAS y A. MUÑOZ (eds.), Tarraco christiana ciuitas, Documenta 24, ICAC, Tarragona, $111-122$

TED'A, 1988-89, El pas de la via Augusta per la mansió de Tàrraco, Butlletí Arqueològic V 10-11, 126-129.

TED'A, 1990, L'amfiteatre romà de Tarragona, la basílica visigòtica i l'església romànica, Memòries d'excavació 3, Tarragona.

YNGUANZO, D., 2012, Control arqueològic $i$ documentació de paraments, c/ Granada, 7, MIGC, Tarragona. 